\title{
Group Learning Through the Lens of Learner Autonomy
}

\author{
Michael K. Ponton \\ Dept. of Higher Education and Learning Technologies, Texas A\&M University-Commerce \\ P.O. Box 3011, Commerce, Texas 75429, United States \\ Tel: 1-757-753-3137Ｅ-mail: Michael.Ponton@tamuc.edu
}

Received: April 17, 2020 Accepted: May 20, 2020 Published: June 4, 2020

doi:10.5296/ijld.v10i2.17144 URL: https://doi.org/10.5296/ijld.v10i2.17144

\begin{abstract}
Learner autonomy describes the individual who exercises personal agency in his or her learning. Similar to an individual, groups - that is, collections of people with a defined purpose often represented by organizational subunits - also engage in intentional learning to support and improve existing processes or identify and pursue new opportunities. The purpose of this theoretical discussion is to characterize aspects of intentional group learning using the theoretical framework associated with learner autonomy. Applied to the group level, notions of agentic learning, modes through which agentic learning is exercised, and regulation will be discussed through this lens of autonomy. This discussion may prove useful in describing how organizational groups learn intentionally and in developing processes that improve such learning.
\end{abstract}

Keywords: learner autonomy, autonomous learning, group learning, organizational learning 


\section{Introduction}

The study of learner autonomy has been associated with the field of self-directed learning and used to describe the individual who shows desire (Meyer, 2001), resourcefulness (Carr, 1999), initiative (Ponton, 1999), persistence (Derrick, 2001), and self-efficacy (Ponton, Carr, Schuette, \& Confessore, 2010) in intentional learning activities. In this manifestation of human agency (i.e., intentional action; cf. Bandura, 1989), the individual proactively directs his or her learning in order to influence personal development in ways that facilitate chosen trajectories. Based upon the individual's value system, desirable outcomes are identified followed by goals and plans that are proactively chosen to accomplish such outcomes (cf. Atkinson, 1982; Vroom, 1964) with autonomous learning enlisted to support requisite personal development (Ponton \& Carr, 1999). Self-regulation in learning is used by the individual to goal direct, plan, monitor, maintain, and measure developmental progress - identifying and invoking changes to the learning plan as necessary - thereby supporting goal accomplishment (Zimmerman, Bonner, \& Kovach, 1996). Self-reflection then determines how well the consequences of accomplishing the selected goal align with the desirable outcomes initially predicted.

Similar to an individual, an organization and its subunits (i.e., members working in concert) also identify desirable outcomes and adopt performance goals and activities intended to accomplish these outcomes (Ponton, 2019). These desirable outcomes may be at the organizational or subunit level; however, even subunit outcomes should support the organization's overall purpose. Such activities are influenced by the group efficacy of the organization's members in selection and perseverance-which helps to explain interorganizational variation in missions, services, products, and successes - and produce consequences that support learning either intentionally via planned learning or unintentionally via unplanned learning. Intentional organizational or group learning is the process that describes how information is purposely acquired, archived, retrieved, and used at the organizational or group level (cf. Ponton, 2019), respectively, to inform future decision making. Although the level of participation, pervasiveness, and extent of impact may be used to differentiate what occurs at the organizational versus the group level, the present discussion will use the term "group learning" throughout regardless of these differentiators as typically there will always be a minority of organizational members involved in catalyzing a given learning activity.

Although a group may learn from its nonlearning activities (i.e., production of goods or delivery of services) either intentionally or unintentionally, it may also intentionally pursue learning activities that inform and influence its nonlearning activities (e.g., improvement of current functions or selection of new functions).

As opposed to unintentional learning that occurs without a goal or plan to learn, groups engage in myriad intentional learning activities adopted to produce desirable group or organizational level outcomes with improved levels of efficiency and productivity. Although learning - unintentional and intentional — can and does occur at the organizational member level, the focus of this discussion is to address intentional learning at the group level; that is, how groups work in a concerted manner with respect to intentional learning activities. As 


\section{Macrothink}

learner autonomy has been extensively discussed using an agentic perspective (cf. Ponton \& Carr, 2016), the organization of the present discussion includes (a) a discussion of the group as a learner, (b) learner autonomy theory, and (c) a conceptual framework of autonomous learning at the individual level projected onto the group level (i.e., group learner autonomy) in order to better understand intentional group learning (i.e., group autonomous learning). Note that this discussion is limited to the learning process, which may prove useful in describing how organizational groups learn intentionally and in developing processes that improve such learning; however, the mechanisms associated with interpersonal dynamics, communication, and the change management needed to implement learned findings are not part of this discussion.

\subsection{The Group as a Learner}

Popplestone and McPherson (1988) defined learning as "acquiring knowledge and skills as the result of experience" (p. 212). As has been historically understood in the study of autonomous and self-directed learning, learning is performed by an individual learner; that is, a single person who exerts control over his or her learning by acting as an agent in making requisite decisions associated with desired learning activities designed to acquire knowledge or skills (cf. Bouchard, 1994; Brockett, 1985; Candy, 1990; Chene, 1983; Confessore \& Confessore, 1994; Garrison, 1989; Guglielmino, 1977; Hiemstra, 1994; Jarvis, 1992; Knowles, 1975; Long, 1989; Mezirow, 1985; Redding \& Aagaard, 1992). This line of inquiry has focused not only on creating a theoretical framework for a learner's agency (i.e., an individual's intentionality with respect to learning) but also on developing facilitative strategies to strengthen such agentic learning. For an individual learner, knowledge and skills become part of the memory system for subsequent recall when needed.

A group is a collection of two or more persons intentionally created to accomplish a given purpose. Ponton (2019) described the organization - that can be equally applied to an organizational group - as a unit of analysis with respect to behavior in general and learning in particular as follows:

Organizational behavior refers to a superordinate perspective of how humans motivationally, intentionally, and capably work in a concerted manner consistent with an organization's mission. Using this same perspective, organizational [or group] learning can be understood as system controlled information acquisition, storage, and retrieval; that is, how the organization [or group] acquires, manages, and uses information. (p. 186)

Thus, similar to an individual, an organization or group can mimic how an individual learns through the "system" described by Ponton (2019) of "acquisition, storage, and retrieval" (p. 186) of knowledge and skills - that is, information applied in a relevant context - that organizational or group members use to either improve current operations, identify new opportunities, or create new operations.

Organizational or group members can use information with automatic response systems or in nonautomatic deliberations. In the automatic scheme, response systems are designed by members to acquire and use information without the need for human mediation. Examples 
include inventory replenishment due to sales, delivery route adjustments due to traffic accidents or poor weather conditions, and environmental regulation in storage facilities due to temperature or humidity fluctuations or variations in inventory with disparate storage requirements. In the nonautomatic scheme, information is considered by members as they engage in data driven decision making. Group learning can play an important role in both schemes: information must be gathered and used to develop optimal automatic response systems, and information must be gathered and used to inform nonautomatic deliberations.

Group learning may be unintentional or intentional. In the unintentional learning perspective, procedures are made more efficient due to rote repetition that improves skill in the implemented procedure (cf. the learning curve concept) thus creating tacit knowledge that is not codified or transferred but rather exists within individual members (Sanchez, 2020). Additionally, current operations may produce consequences that provide information for members to consider with respect to current procedures. The unintentional view represents an experiential perspective in which experience is merely the process of doing rather than an experience that is designed as a learning activity with a predetermined learning goal, a learning plan, and an evaluative procedure. In contrast, intentional learning represents an agentic perspective in the design of a learning activity that incorporates forethought to establish a goal and create a learning plan, self-regulation to persist and correct the learning plan as necessary, and self-reflection to learn from the learning activity (cf. Bandura, 1986) by creating explicit knowledge that is codified and transferable (Sanchez, 2020). An intentional learning activity may coincide with an existing procedure (e.g., a program evaluation) or it may be an activity completely distinct from current procedures (e.g., an exploratory study designed to identify new opportunities). Note that institutional knowledge - knowledge that is uncodified but is transferred between organizational members who hold such knowledge in their memory (i.e., institutional memory) - can be developed via activities that may or may not have an intentional learning purpose. The focus of the ensuing discussion in on the agentic perspective in which a group engages in intentional learning to improve, expand, or create select functions.

\section{Learner Autonomy}

Confessore (1992) suggested the importance of four conative (i.e., related to intention) factors in self-directed learning: desire, resourcefulness, initiative, and persistence. These four factors became the impetus for four doctoral research studies that focused on preconation (Meyer, 2001) and conation (Carr, 1999; Derrick, 2001; Ponton, 1999) in developing associated theoretical frameworks and instrumentation. Based upon the work of Bandura (1997), self-efficacy was studied as an additional preconative factor (cf. Ponton et al., 2010). All five have been theoretically argued as important constructs associated with learner autonomy, described as a personality characteristic of exhibiting personal agency - that is, intentional action-in learning (Ponton, 1999; Ponton \& Carr, 2000), with significant interfactor relationships using associated measures (Ponton et al., 2010).

Meyer (2001) created a theoretical framework for desire in learner autonomy based on an adult's ability to act intentionally (i.e., preconative). Meyer's framework focused on three factors: freedom, power, and change. Ponton, Carr, and Derrick (2004) argued that desire 
should influence resourcefulness, initiative, and persistence (i.e., conation) through the mediating effect of self-efficacy. In discussing Meyer's work, Park and Confessore (2002) asserted the following: "[Meyer's] work on desire to learn has been treated as an effort to understand the precursors to the development of intentions related to learning" (p. 289). Meyer's work led to the development of the Inventory of Learner Desire.

Carr (1999) conceptualized resourcefulness primarily using the self-control theory of Rosenbaum (1989). In Carr's work, resourcefulness as an aspect of learner autonomy consists of four behaviors: anticipating the future rewards of current learning, prioritizing current learning over nonlearning activities, choosing current learning over nonlearning activities, and solving problems associated with desired learning (i.e., plan, anticipate consequences, and develop contingencies for impediments). Ponton, Carr, and Derrick $(2004,2005)$ showed that resourcefulness plays a major role in learner autonomy due to parallel constructs related to motivation; in this regard, their work provided the impetus for the study of self-efficacy as a related construct. Carr's work led to the development of the Inventory of Learner Resourcefulness.

Ponton (1999) argued that initiative is a 5-factor syndrome of the following cooccurring behaviors: goal-directedness, action-orientation, active approach to problem solving, persistence in overcoming obstacles, and self-startedness. Goal-directedness refers to the creation of goals with characteristics that provide maximum motivation and working toward their accomplishment. Action-orientation refers to the rapidity of moving from the creation of an intention to act to the act itself. An active approach to problem solving refers to the creation of solutions to one's own problems without waiting for others to do so. Persistence in overcoming obstacles refers to engaging in continued intended action despite the presence of impediments. Self-startedness refers to engaging in an intended action either initially or after a period of inactivity without the need for others to prompt such action. Ponton's work led to the development of the Inventory of Learner Initiative.

Derrick (2001) defined persistence in learner autonomy as including the following factors: goal directedness, self-regulation, and volition. Derrick's conceptualization of goal-directedness differs from Ponton's (1999) in that the focus of the former is on persistence toward goal accomplishment whereas the latter is on adopting goals that create maximum motivation (Ponton \& Rhea, 2006); in this regard, both conceptualizations are important in understanding goal-directed action. "Volition is a post-decisional process whereby once one decides (i.e., intends) to engage in a behavior, volition refers to the maintenance of motivation in proceeding from intention to behavior" (Ponton \& Carr, 2000, p. 277); thus, it is an essential concept in understanding perseverant behavior (cf. Heckhausen \& Kuhl, 1985). Derrick's work led to the development of the Inventory of Learner Persistence.

Bandura (1997) discussed the important mediating effect of self-efficacy - a perception of requisite capability to be successful in a given domain of activity - in cognitive motivation (i.e., expectancy value, goal, and attribution theories). Ponton, Derrick, Hall, Rhea, and Carr (2005) continued this line of reasoning and developed instrumentation to measure self-efficacy in autonomous learning (i.e., the Appraisal of Learner Autonomy). The Learner Autonomy 
Profile includes the Inventories of Learner Desire, Resourcefulnes, Initiative, and Persistence (licensed to Human Resource Development Enterprises, HRDE) as well as the Appraisal of Learner Autonomy (available in the public domain; see Ponton, Derrick, Hall et al., 2005) and is used by HRDE for its international coaching efforts to strengthen the learner autonomy of its clients.

Based upon the theoretical frameworks developed for the aforementioned constructs of desire, resourcefulness, initiative, persistence, and self-efficacy, learner autonomy can be argued as similarly applicable to the group level - that is, group learner autonomy - as well as to the individual level with respect to learning endeavors. In order for a group to engage in intentional learning, it must (a) have the freedom as well as the power to do so (cf. desire); (b) believe that it can engage in a learning activity that will yield successful findings (cf. self-efficacy); (c) anticipate that a learning activity has future value so that it will prioritize learning, choose to learn, and resolve any issues associated with learning (cf. resourcefulness); (d) not just intend to learn but rather move from an intention to action rapidly, self-start learning activities with specific learning goals, solve problems associated with learning activities, and persist in overcoming any obstacles (cf. initiative); and (e) persist toward the learning goals while regulating action to maximize volition (cf. persistence).

\section{Autonomous Learning}

Ponton (1999) defined autonomous learning as "an agentive learning process in which . . . conative factors ... are manifest" (p. xiii) and wrote that "learner autonomy can be viewed as the psychological undergirding that leads to the behaviors associated with the process of autonomous learning” (p. 14). In this regard, autonomous learning represents the agentic actions associated with engaging in a learning activity as a manifestation of learner autonomy. Some of these actions are overt behaviors (e.g., actual study) whereas others are not observable (e.g., goal setting) but are nonetheless critical to having a successful agentic learning experience. There are three modes through which agency is manifest-individual, proxy, and collective (Bandura, 2006) - that Ponton (2016) discussed in differentiating autonomous learning with self-directed learning using social cognitive theory's three environmental forms - created, selected, and imposed (Bandura, 1997) — as venues for autonomous learning.

The created environment represents new conditions that a person experiences which exist due to the person's agency to create them. With respect to learning, a created environment is a learning activity that is created by exercising the learner's agency in order to satisfy his or her requirements; as such, it will include a goal, information, study activities, and an evaluation. The activity can be created by the learner (i.e., individual agency), knowledgeable others who the learner enlists for the creation (i.e., proxy agency), or knowledgeable others who work together with the learner for the creation (i.e., collective agency); however, despite the mode through which the agency is exercised, it is the learner acting as an agent who catalyzes the creation of the learning activity whether or not others are enlisted to create or help create the learning activity.

There are also environmental conditions that currently exist thereby offering a repertoire of experiences from which a person can make an intentional selection. With respect to learning, a 
selected environment is a learning activity that is selected by exercising the learner's agency in order to satisfy his or her requirements. Existing continuing education workshops, college courses, and programmed training are examples of such learning activities. The activity can be selected by the learner (i.e., individual agency), knowledgeable others who the learner enlists for the selection (i.e., proxy agency), or knowledgeable others who work together with the learner for the selection (i.e., collective agency); however, despite the mode through which the agency is exercised, it is the learner acting as an agent who catalyzes the selection of the learning activity whether or not others are enlisted to select or help select the learning activity.

The imposed environment refers to environmental conditions that a person has no control over in either creation or selection; thus, a person's intersection with the conditions is due to fortuity (Bandura, 1982). As there is no proactive agency, personal agency is invoked in a reactionary manner; that is, reactive agency describes how the agent chooses to engage with the imposed environment. With respect to learning, an imposed environment is an agentic learning activity when the person chooses to learn (i.e., engage in sense making) from the experience. Such learning can be defined by the learner (i.e., individual agency), knowledgeable others who the learner enlists for sense making (i.e., proxy agency), or knowledgeable others who work together with the learner for sense making (i.e., collective agency); however, despite the mode through which the agency is exercised, it is the learner acting as an agent who catalyzes sense making from the imposed experience whether or not others are enlisted to make sense of or help make sense of the experience.

Creating learning activities, selecting learning activities, or making sense of an imposed environment via any mode of agency have been described by Ponton (2016) as autonomous learning activities. In this regard, any learning that is intentionally pursued due solely to an agent's discretion is autonomous learning. Successful autonomous learning is predicated upon the degree to which learner autonomy-desire, resourcefulness, initiative, persistence, and self-efficacy - exists; Ponton and Carr (2000) argued that learner autonomy helps the learner to perceive the existence of opportunity, time, importance, urgency, and means- "OTIUM checks that [if satisfied] . . . result in the additional instigation of the action tendency" (Blankenship, 1985, p. 168) — to learn.

Using this agentic framework, group autonomous learning can be conceptualized in a similar manner; that is, as a manifestation of group learner autonomy. When a group decides to engage in learning, it can rely solely on itself (i.e., individual agency), rely on others (i.e., proxy agency), or work together with others (i.e., collective agency) to create a learning activity (i.e., created environment), select a learning activity (i.e., selected environment), or make sense of a fortuitous happening (i.e., imposed environment). 


\section{LEARNING ENVIRONMENT}

\begin{tabular}{|c|c|c|c|c|}
\hline & & Created & Selected & Imposed \\
\hline & Collective & 1 & 4 & 7 \\
\hline \multicolumn{5}{|l|}{ MODE } \\
\hline OF & Proxy & 2 & 5 & 8 \\
\hline \multicolumn{5}{|l|}{ AGENCY } \\
\hline & Individual & 3 & 6 & 9 \\
\hline
\end{tabular}

Figure 1. Matrix of learning environments and modes of agency

Figure 1 provides a matrix of learning possibilities in which a group can engage. Examples of each of the nine included possibilities are as follows:

Created learning environment and collective mode: A car manufacturer's production subunit wants to learn how to increase the efficiency of its assembly plant and works together with a consultant to develop an evaluation plan of its current assembly operation;

Created learning environment and proxy mode: A car manufacturer's production subunit wants to learn how to increase the efficiency of its assembly plant and hires a consultant to develop an evaluation plan of its current assembly operation;

Created learning environment and individual mode: A car manufacturer's production subunit wants to learn how to increase the efficiency of its assembly plant and develops in-house an evaluation plan of its current assembly operation;

Selected learning environment and collective mode: A human resource development department wants to provide sexual harassment training to the firm's employees and works together with a consultant to select a training package from existing packages;

Selected learning environment and proxy mode: A human resource development department wants to provide sexual harassment training to the firm's employees and hires a consultant to select a training package from existing packages;

Selected learning environment and individual mode: A human resource development department wants to provide sexual harassment training to the firm's employees and selects in-house a training package from existing packages;

Imposed learning environment and collective mode: A chemical plant's board of directors wants to learn the cause of a plant mishap in order to avoid future mishaps and works together with a consultant to study the situation;

Imposed learning environment and proxy mode: A chemical plant's board of directors wants to learn the cause of a plant mishap in order to avoid future mishaps and hires a consultant to study the situation; and 
Imposed learning environment and individual mode: A chemical plant's board of directors wants to learn the cause of a plant mishap in order to avoid future mishaps and works in-house to study the situation.

Note that in these simple examples, there are multiple levels of organizations that determine their own mode of agency for action. In a previous example (see example 2), a car manufacturer's production subunit wants to learn how to increase the efficiency of its assembly plant and hires a consultant to develop an evaluation plan of its current assembly operation. In this situation, the production subunit (first level organization) is exerting proxy agency to create a learning environment by hiring the consultant (second level organization) to create the evaluation plan. The consultant can exert its own agency by choosing which mode (collective, proxy, or individual) to use to either create a new evaluation plan or select from an existing evaluation plan (or, perhaps, customize an existing plan) in order to ultimately provide the car manufacturer with its own evaluation plan. The salient point is that in all nine examples, the first level organization (i.e., car manufacturer's production subunit, human resource development department, or chemical plant board of directors) identified a learning need (how to increase the efficiency of its assembly plant, provide sexual harassment training, the cause of a plant mishap, respectively) and exerted its own agency in determining the mode of agency — collective, proxy, or individual — to enlist in order to satisfy this need.

\section{Conclusion}

A great deal of theorizing and research has been conducted on learner autonomy and manifest autonomous learning (cf. Ponton \& Carr, 2016). Such work has addressed not only the building of a conceptual framework but also the methods to strengthen learner autonomy thereby maximizing the benefits of intentional learning. The present discussion has posited that there can be a theoretical supplanting of the individual with the group as the learner in order to better understand and hopefully strengthen group learner autonomy. In so doing, intentional group learning invoked to improve current operations, identify new opportunities, or create new functions may be optimized thereby increasing group achievement of desirable outcomes. As this discussion incorporated a heuristic approach, it is limited by a lack of research used for substantive theory building.

Because of the extensive, multidecade theorizing that exists on learner autonomy, it would be impossible to fully discuss all of the concepts and conceptual nuances associated with using the organization or group as the unit of analysis instead of the individual. Instead, the purpose of this discussion was to address learner autonomy and manifest autonomous learning at a superordinate theoretical level in order to support the thesis that learner autonomy is a valuable lens through which to study, understand, and potentially improve intentional group learning. Future research should focus on extant literature that describes strategies used to promote learner autonomy at the individual level but applied to the group level.

\section{References}

Atkinson, J. W. (1982). Old and new conceptions of how expected consequences influence actions. In N. T. Feather (Ed.), Expectations and actions: Expectancy-value models in 
psychology (pp. 17-52). Hillsdale, NJ: Lawrence Erlbaum Associates.

Bandura, A. (1982). The psychology of chance encounters and life paths. American Psychologist, 37(7), 747-755. https://doi.org/10.1037/0003-066X.37.7.747

Bandura, A. (1986). Social foundations of thought and action: A social cognitive theory. Englewood Cliffs, NJ: Prentice Hall.

Bandura, A. (1989). Human agency in social cognitive theory. American Psychologist, 44(9), 1175-1184. https://doi.org/10.1037/0003-066X.44.9.1175

Bandura, A. (1997). Self-efficacy: The exercise of control. New York, NY: W. H. Freeman and Company.

Bandura, A. (2006). Toward a psychology of human agency. Perspectives on Psychological Science, 1(2), 164-180. https://doi.org/10.1111/j.1745-6916.2006.00011.x

Blankenship, V. (1985). The dynamics of intention. In M. Frese \& J. Sabini (Eds.), Goaldirected behavior: The concept of action in psychology (pp. 161-170). Hillsdale, NJ: Lawrence Erlbaum Associates.

Bouchard, P. (1994). Self-directed professionals and autodidactic choice. In H. B. Long \& Associates (Eds.), New ideas about self-directed learning (pp. 121-137). Norman, OK: Oklahoma Research Center for Continuing Professional and Higher Education of the University of Oklahoma.

Brockett, R. G. (1985). The relationship between self-directed learning readiness and life satisfaction among older adults. Adult Education Quarterly, 35(4), 210-219. https://doi.org/10.1177/0001848185035004003

Candy, P. D. (1990). The transition from learner-control to autodidaxy: More than meets the eye. In H. B. Long \& Associates (Eds.), Advances in research and practice in self-directed learning (pp. 9-46). Norman, OK: Oklahoma Research Center for Continuing Professional and Higher Education of the University of Oklahoma.

Carr, P. B. (1999). The measurement of resourcefulness intentions in the adult autonomous learner (Doctoral dissertation). Retrieved from ProQuest Dissertations and Theses database. (Accession No. 304520149)

Chene, A. (1983). The concept of autonomy in adult education: A philosophical discussion. Adult Education Quarterly, 34(1), 38-47. https://doi.org/10.1177/0001848183034001004

Confessore, S. J., \& Confessore, G. J. (1994). Learner profiles: A cross-sectional study of selected factors associated with self-directed learning. In H. B. Long \& Associates (Eds.), New ideas about self-directed learning (pp. 201-227). Norman, OK: Oklahoma Research Center for Continuing Professional and Higher Education of the University of Oklahoma.

Confessore, G. J. (1992). An introduction to the study of self-directed learning. In G. J. Confessore \& S. J. Confessore (Eds.), Guideposts to self-directed learning: Expert commentary on essential concepts (pp. 1-6). King of Prussia, PA: Organization Design and 
Development.

Derrick, M. G. (2001). The measurement of an adult's intention to exhibit persistence in autonomous learning (Doctoral dissertation). Retrieved from ProQuest Dissertations and Theses database. (Accession No. 276280161)

Garrison, D. R. (1989). Facilitating self-directed learning: Not a contradiction in terms. In H. B. Long \& Associates (Eds.), Self-directed learning: Emerging theory \& practice (pp. 53-62). Norman, OK: Oklahoma Research Center for Continuing Professional and Higher Education of the University of Oklahoma.

Guglielmino, L. M. (1977). Development of the self-directed learning readiness scale (Doctoral dissertation). Retrieved from ProQuest Dissertations \& Theses Global. (Accession No. 7806004)

Heckhausen, H., \& Kuhl, J. (1985). From wishes to action: The dead ends and short cuts on the long way to action. In M. Frese \& J. Sabini (Eds.), Goal-directed behavior: The concept of action in psychology (pp. 134-157). Hillsdale, NJ: Lawrence Erlbaum Associates.

Hiemstra, R. (1994). Self-directed learning. In T. Husen \& T. N. Postlethwaite (Eds.), The international encyclopedia of education (2nd ed.). Oxford, UK: Pergamon Press.

Jarvis, P. (1992). Free-will, freedom and self-directed learning. In H. B. Long \& Associates (Eds.), Self-directed learning: Application and research (pp. 97-117). Norman, OK: Oklahoma Research Center for Continuing Professional and Higher Education of the University of Oklahoma.

Knowles, M. S. (1975). Self-directed learning: A guide for learners and teachers. Chicago, IL: Follett.

Long, H. B. (1989). Self-directed learning: Emerging theory and practice. In H. B. Long \& Associates (Eds.), Self-directed learning: Emerging theory \& practice (pp. 1-11). Norman, OK: Oklahoma Research Center for Continuing Professional and Higher Education of the University of Oklahoma.

Meyer, D. T. (2001). The measurement of intentional behavior as a prerequisite to autonomous learning (Doctoral dissertation). Retrieved from ProQuest Dissertations and Theses database. (Accession No. 304693210)

Mezirow, J. (1985). Concept and action in adult education. Adult Education Quarterly, 35(3), 142-151. https://doi.org/10.1177/0001848185035003003

Park, E., \& Confessore, G. J. (2002). Development of new instrumentation: Validation of the Learner Autonomy Profile beta version. In H. B. Long \& Associates (Eds.), Twenty-first century advances in self-directed learning (pp. 289-306). Schaumburg, IL: Motorola University Press.

Ponton, M. K. (1999). The measurement of an adult's intention to exhibit personal initiative in autonomous learning (Doctoral dissertation). Retrieved from ProQuest Dissertations and 
Theses database. (Accession No. 304520327)

Ponton, M. K. (2016). An agentic perspective contrasting autonomous learning with self-directed learning. In M. K. Ponton \& P. B. Carr (Eds.), Autonomous and self-directed learning: Agentic perspectives (pp. 49-62). Chesapeake, VA: Watertree Press.

Ponton, M. K. (2019). Organizational behavior and agency: A conceptual analogy with individual agency. International Journal of Education and Social Science Research, 2(5), 185-191.

Ponton, M. K., \& Carr, P. B. (1999). A quasi-linear behavioral model and an application to self-directed learning (NASA Technical Memorandum 209094). Hampton, VA: NASA Langley Research Center.

Ponton, M. K., \& Carr, P. B. (2000). Understanding and promoting autonomy in self-directed learning. Current Research in Social Psychology, 5(19), 271-284. Retrieved from http://www.uiowa.edu/crisp

Ponton, M. K., \& Carr, P. B. (Eds.). (2016). Autonomous and self-directed learning: Agentic perspectives. Chesapeake, VA: Watertree Press.

Ponton, M. K., Carr, P. B., \& Derrick, M. G. (2004). A path analysis of the conative factors associated with autonomous learning. International Journal of Self-Directed Learning, 1(1), 59-69.

Ponton, M. K., Carr, P. B., Schuette, C. T., \& Confessore, G. J. (2010). Self-efficacy and the Learner Autonomy Profile. International Journal of Self-Directed Learning, 7(2), 54-63.

Ponton, M. K., Derrick, M. G., \& Carr, P. B. (2005). The relationship between resourcefulness and persistence in adult autonomous learning. Adult Education Quarterly, 55(2), 116-128. https://doi.org/10.1177/0741713604271848

Ponton, M. K., Derrick, M. G., Hall, J. M., Rhea, N. E., \& Carr, P. B. (2005). The relationship between self-efficacy and autonomous learning: The development of new instrumentation. International Journal of Self-Directed Learning, 2(1), 50-61.

Ponton, M. K., \& Rhea, N. E. (2006). Autonomous learning from a social cognitive perspective. New Horizons in Adult Education and Human Resource Development, 20(2), $38-49$.

Popplestone, J. A., \& McPherson, M. W. (1988). Dictionary of concepts in general psychology. Westport, CT: Greenwood Press.

Redding, T. R., \& Aagaard, L. (1992). A descriptive investigation of the construct of self-direction. In H. B. Long \& Associates (Eds.), Self-directed learning: Application and research (pp. 147-161). Norman, OK: Oklahoma Research Center for Continuing Professional and Higher Education of the University of Oklahoma.

Rosenbaum, M. (1989). Self-control under stress: The role of learned resourcefulness. Advances in Behaviour Research and Therapy, 11, 249-258. https://doi.org/10.1016 
/0146-6402(89)90028-3 2020, Vol. 10, No. 2

Sanchez, R. (n.d.). "Tacit knowledge" versus "explicit knowledge” approaches to knowledge management practices. Retrieved from https://research-api.cbs.dk/ws/portalfiles/portal 159100512/7224.pdf

Vroom, V. H. (1964). Work and motivation. New York, NY: John Wiley and Sons.

Zimmerman, B. J., Bonner, S., \& Kovach, R. (1996). Developing self-regulated learners: Beyond achievement to self-efficacy. Washington, DC: American Psychological Association.

\section{Copyright Disclaimer}

Copyright for this article is retained by the author(s), with first publication rights granted to the journal.

This is an open-access article distributed under the terms and conditions of the Creative Commons Attribution license (http://creativecommons.org/licenses/by/4.0/). 